\title{
Student Mental Effort on Integrated Science Curriculum Content Analysis and Pedagogy
}

\author{
I. Permana ${ }^{*}$, H Firman $^{*}$, S Redjeki ${ }^{*}$, I Hamidah ${ }^{*}$, dan N Safitri ${ }^{* *}$ \\ ${ }^{*}$ University of Pakuan, Bogor, Indonesia \\ **) Indonesia University of Education, Bandung, Indonesia \\ Corresponding Author: irvanpermana@unpak.ac.id
}

\begin{abstract}
This study aims to determine the profile and outlook of prospective elementary school teachers on mental effort on Integrated Science curriculum materials integrated content and pedagogy as well as to know the pattern of integrated IPA curriculum analysis integrated content and pedagogy. The subjects of the research are prospective teachers of elementary school one of the universities in the city of Bogor semester 5 class of 2016/2017 as many as 31 students. The data needed to answer the problem of qualitative data. The data were collected with several techniques such as observation and questionnaires. The main questions asked in this study are the questions asked to prospective elementary school teachers. Principal questions asked to prospective teachers of elementary school, the question to reveal the mental business of prospective elementary school teachers in the curriculum analysis courses. Based on the results of research, applied lecture strategy resulted in low mental effort. In the curriculum analysis lectures found increased mental effort caused by material complexity.
\end{abstract}

Keywords: mental effort, integrated science, integrated content and pedagogy lectures, curriculum analysis

\section{INTRODUCTION}

Integrated learning has a positive impact on learning outcomes (Bravo et.al, 2014; Sandholtz and Ringstaff, 2014; Hacieminoglu, 2014; Wilson, et al, 2015). Increased learning outcomes in science and science education can be done by integrating approaches (Hacieminoglu, 2014), strategies (Wilson, et al. 2015; Bravo et al. 2014; Sandholtz and Ringstaff, 2014), methods (Gerde et.al, 2013), and content (Nilsson and Loughran, 2012). Research that integrates content with pedagogy for elementary school teachers is successful in improving perceptions and improving students' readiness to become teachers. (Bravo et.al, 2014; Sandholtz and Ringstaff, 2014; Hacieminoglu, 2014; Wilson, et al., 2015). However, learning in accordance with the nature of science has not been completed during the lecture (Hacieminoglu, 2014, Bravo, 2014), so that in the field the teacher returns to old teaching habits. Integrated IPA content loading and pedagogical integration for prospective elementary school teachers is required.

Basically, the learning process is related to the ability of memory to receive information. Each person's memory capability is different, everyone's memory has a limited capacity to receive information from one another. The existence of limited ability will cause a person to be heavy and burdened when it must receive a lot of information. This is explained also in the theory of cognitive load (Cognitive Load Theory). Cognitive Load Theory (CLT) aims to predict learning outcomes with regard to the capabilities and limitations of human cognitive understanding. This theory can be applied to various learning environments because of the design characteristics of teaching materials related to the principles of human information processing. Considering the demands on cognitive resources induced by the complexity of the information to be learned, the way in which learning is presented to learners, and the experience and knowledge of previous learners, the CLT aims to predict what makes learning successful and how learning can be effectively supported by instruction and instruction (Plass, Moreno \& Brunken, 2010).

Principles of application Theory of cognitive load in learning is to use the work of working memory. Understanding of how cognitive processes work and learners' work memory is the basis for improving learning according to student learning (Ong and Natsir, 2015; Yung and Paas, 2015). Various studies using the Cognitive Load Theory as a framework for developing a learning design show positive results (Ong and Natsir, 2015; Yung and Paas, 2015).

Based on the above problems, it is necessary to implement learning that integrates science materials, namely Physics, Biology, Chemistry, and IPBA 
materials to facilitate student conceptual integration. Such learning is in line with Fogarty's (1991) opinion that the curriculum can be used as the basis for the integration of teaching materials. Lessons that can facilitate students to carry out conceptual integration in lectures. SD science lesson is a learning that integrates materials of physics, biology, chemistry, and IPBA. Based on the opinion of Sweller (2005) and Mayer (2001), the learning that integrates the interrelationship aims to equip the importance of Epistemic, Biological, Chemical, and IPBA in epistemology, and develop positive attitudes and perceptions in the science lesson of SDA to reduce students' cognitive burden .

Research on the application of cognitive load theory needs to take measurements on the components of cognitive load to measure its effectiveness. Extraneous Cognitive Load (ECL) measurements are done through the mental effort of the students required in the curriculum analysis course.

\section{RESEARCH METHODS}

The subject of this research is prospective teacher of elementary school one of college in Bogor city 5 th semester of class of 2016/2017 as many as 31 students. The data collected are qualitative data needed to answer the problem of mental effort (ECL) of prospective teacher students in Integrated Science curriculum analysis materials integrated content and pedagogy. The data were collected by observation techniques and questionnaires. Observations were made to capture data on lecture strategies. Observations were addressed to lecturers and prospective students during the lecture. While the questionnaire is given to prospective teacher students to obtain mental business data on Integrated Science curriculum analysis materials and content pedagogy.

\section{RESULTS AND DISCUSSION}

\section{a. Integrated lecturing strategy of IPA content and pedagogy}

The implementation strategy of IPA education lectures that implement the integration of IPA and pedagogical content is captured through observation and field observation activities during the lecture. Observation activities at IPA Education lectures that implement integration of IPA and pedagogical content on grade IV, V and VI curriculum analysis materials.

Based on the observation result and field notes of IPA education in High School grade which apply integration of IPA content and pedagogy, it is found the sequence of lecture steps as lecture strategy. The sequence of lecture steps on grade IV, V and VI curriculum analysis materials are 1) Assignment of groups (2 persons) to search for literature on IPA content, elementary school learning articles (Bahasa Indonesia) and relevant articles (English), assignments this group is given 1 week before the lecture, 2) minimal concept analysis in selected KD, 3) Analysis of strategy demanded in selected KD, 4) Analysis of thinking ability, PPP, attitude and Psychomotor potentially developed in selected KD 5) Discussion of results Analysis, and 6) Designing learning based on $\mathrm{KD}$ analysis and article search results.

\section{b. Profile of mental effort of prospective elementary school teachers on integrated lectures of science content and pedagogy}

The mental effort of prospective elementary school teachers on integrated lectures of IPA content and pedagogy was collected using questionnaires (questionnaire sheets). The questionnaire sheets are used to measure students' mental effort in grade IV, V and VI curriculum analysis.

The questionnaire sheet contains statements that reveal the suitability of the lecture strategy with the lecture material presented to the students. The scores of analytical skills are converted in qualitative terms by referring to the categorization of Arikunto (2012).

Table 1. Rubric scores of mental effort instruments

\begin{tabular}{ll}
\hline Score & category \\
\hline 4 & Very helpful \\
3 & helpful \\
2 & Less helpful \\
1 & Not helpful \\
\hline
\end{tabular}

The rubric in Table 1. is used to obtain a mental effort score. The score describes the ease of students following the lecture process.

Table 2. Categorization of mental effort

\begin{tabular}{lcl}
\hline Score & $\begin{array}{l}\text { Conversion scale } \\
\mathbf{1 0 0}\end{array}$ & $\begin{array}{l}\text { Qualitative } \\
\text { category }\end{array}$ \\
\hline $3,40<\mathrm{x} \leq 4,00$ & $80<\mathrm{x} \leq 100$ & Very low \\
$2,80<\mathrm{x} \leq 3,40$ & $60<\mathrm{x} \leq 80$ & low \\
$2,20<\mathrm{x} \leq 2,80$ & $40<\mathrm{x} \leq 60$ & medium \\
$1,60<\mathrm{x} \leq 2,20$ & $20<\mathrm{x} \leq 40$ & high \\
$1,00<\mathrm{x} \leq 1,60$ & $0<\mathrm{x} \leq 20$ & Very high \\
\hline (Arikunto, 2012) & &
\end{tabular}

In Table 2. there is a categorization used to categorize the mental business of prospective elementary school teachers. Conversion scores are used to get 100 scale scores so that all values obtained in this study have values of the same scale ..

Based on the results of the questionnaire given to the students of SD candidates in the lectures on integrated content of science and pedagogy on the material of the IV, V, and VI elementary school curriculum, it was found that low mental effort was found to be greater than the low and medium mental effort. While mental effort in the category of very low and medium have the same percentage. Recapitulation of the result of questionnaire of mental effort in the 
lecture integrated with science content and pedagogy on the subject matter of curriculum data of elementary school class IV, V, and VI there are three categories of mental effort of elementary student candidate teacher that is in very low, low, and medium category.

The percentage of mental business category of prospective elementary school teachers on the grade $\mathrm{IV}, \mathrm{V}$, and VI curriculum analysis materials is shown in Figure 1.

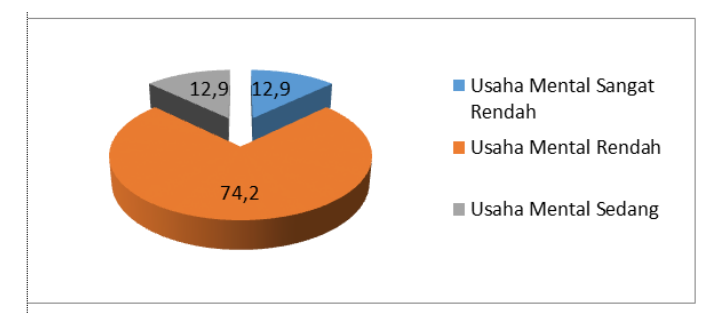

Figure 1. Pie diagram of the mental effort of prospective elementary school teachers on grade IV, V, and VI grade curriculum analysis materials

Based on the figure 1 , the mental effort of prospective elementary school teachers on grade IV, V and VI $12.9 \%$ elementary school curriculum is in very low category, $74.2 \%$ is in the low category, and $12.9 \%$ are in the medium category. This shows a decrease in the mental effort of the students in the third meeting of the fourth grade curriculum, V, and VI, where there is a medium category mental effort with the same percentage of mental effort in very low category. And mental effort in the low percentage categ ory exceeds the mental effort of the category is very low.

The mental effort describes the working memory of the students in processing information. The mental effort is measured by a questionnaire given at the end of the course for one semester. In this research, the mental effort of prospective teacher students is categorized low if the prospective teacher finds it easy to understand the explanations and questions of the lecturer, perform the task of making the product, understand the friend's explanation and understand the material.

In the Curriculum Analysis materials, the students' mental business prospects seem to be improving. Sweller and Chandler (1994) mentioned that easy material does not overload the working memory so there is still room to form new knowledge schemes. None of the prospective teachers on the first and second materials stated that the lecture strategy was less helpful. In the third material, there is one student teacher who stated that less lectures help him understand the material.

In the fourth grade elementary school curriculum analysis materials, V and VI the students' mental efforts are increasing. There are $12.9 \%$ (Figure 1) prospective teachers who require greater mental effort (moderate mental effort). The condition of improvement in this material may be due to the lack of prior knowledge of the students of the teacher candidate. Kalyuga (2011) mentions this with an inadequate prior knowledge situation. This situation is a condition in which the prospective student does not have sufficient initial knowledge to process the new information in his working memory, causing cognitive overload. This situation can increase extraneous cognitive load. The lack of relevant initial knowledge to process the information obtained leads students to use other endeavors than their cognitive abilities (Hindriana and Rahmat, 2014). This is likely to lead to increased mental effort.

The complexity of the material is also one of the factors that decreases the ability of information analysis of prospective teachers (Sweller and Chandler, 1994). Compared with the previous material, curriculum analysis has a high material complexity. Morrienboer and Sweller (2005) suggest for materials that have high levels of interactivity elements, the reduction of extraneous cognitive load is necessary to provide space for working memory in forming a knowledge scheme. Based on that statement for material eight that has a high material complexity needs to be considered to lower mental effort. A decrease in mental effort can lead to extraneous cognitive load so as to give more space to working memory and not cause cognitive overload.

\section{CONCLUSION}

Integrated lectures of science content and pedagogy reveal the mental effort of prospective elementary school teachers in attending the IPA Elementary Education lecture on the materials for making the analysis of grade IV, V and VI curriculum. The result of data analysis found that applied lecture strategy resulted in low mental effort. The increased mental effort is shown in the lectures of curriculum analysis cause'd by the complexity of the lecture material.

\section{REFERENCES}

Arikunto, S. 2010. Prosedur Penelitian, Satuan Pendekatan dan Praktek. Jakarta: Rineka Cipta.

Bravo, et.al. 2014. Possibilities and Limits of Integrating Science and Diversity Education in Preservice Elementary Teacher Preparation. J Sci Teacher Educ. 25:601-619.

Fogarty, R. 1991. How to integrate the curricula. Illionis: Skylight Publishing. Inc.

Gerde, Wasik and Schachter. 2013. Using the Scientific Method to Guide Learning: An Integrated Approach to Early Childhood Curriculum. Early Childhood Educ J. 41:315-323. 
Hacieminoglu. 2014. How In-service Science Teachers Integrate History and Nature of Science in Elementary Science Courses. Educational Sciences: Theory \& Practice. 14(1), 353-372.

Hindriana, A. F. \& Rahmat, A. 2014. "Beban Kognitif Mahasiswa Dalam Pembelajaran Fungsi Terintegrasi Struktur Tumbuhan Berbasis Dimensi Belajar”. Jurnal Ilmu Pendidikan.

Kalyuga. 2011. Cognitive Load Theory: How Many Types of Load Does It Really Need?. Educ Psychol Rev. 23:1-19.

Mayer, R, E. Heiser, J. \& Lonn, S. 2001. Cognitive constraints on multimedia learning: when presenting more material results in less understanding. Journal of Educational Psychology, 93, p. 187-198

Nilsson and Loughran. 2012. Exploring the Development of Pre-Service Science Elementary Teachers' Pedagogical Content Knowledge. J Sci Teacher Educ. 23:699-721.

Ong and Tasir. 2015. Self-instructional module based on cognitive load theory: a study on information retention among trainee teachers. Education Tech Research Dev. 63:499-515.

Plass, Jan L., Moreno, R., dan Brunken, R. 2010. Cognitive Load Theory. Cambridge: University

Press.Kalyuga, S. 2011 Informing: A cognitive load perspective. The International Journal of an Emerging Transdiscipline, 4(1)

Sandholtz and Ringstaff. 2014. Inspiring Instructional Change in Elementary School Science: The Relationship Between Enhanced Self-efficacy and Teacher Practices. J Sci Teacher Educ. 25:729751.

Sweller, John and Chandler, Paul. 1994. "Why Some Material Is Difficult to Learn" Cognition and Instruction. 12 (3), 185-223.

Sweller. J. 2005. Implications of cognitive load theory for multimedia learning. In R.E, Mayer (Ed), The Cambridge Handbook of Multimedia Learning. New York: Cambridge University Press.

Wilson, McGlasson and Bradbury. 2015. Integrating Service-Learning Pedagogy for Preservice Elementary Teachers' Science Identity Development. J Sci Teacher Educ. 26:319-340

Yung and Paas. 2015. Effects of Cueing by a Pedagogical Agent in an Instructional Animation: A Cognitive Load Approach. Educational Technology \& Society. 18 (3), 153-160 